\title{
Inherited predisposition to chronic lymphocytic leukemia
}

\author{
Jennifer R Brown, MD, PhD \\ Department of Medical Oncology, Dana-Farber Cancer Institute, 44 Binney Street, Boston, MA \\ 02115, USA, and Department of Medicine, Harvard Medical School, Boston, MA 02115, USA, Tel.: \\ +1617 632 4894, Fax: +1 617582 7909, jbrown2@partners.org
}

\section{Abstract}

Inherited susceptibility to chronic lymphocytic leukemia (CLL) has been recognized for decades. Approximately $10 \%$ of individuals with CLL report a family history of CLL or a related lymphoproliferative disorder, and genetic predisposition is the best understood risk factor for CLL. Studies of familial CLL have suggested that the disease features are largely similar to sporadic CLL, although recent data suggest that familial CLL may more commonly show somatic hypermutation of the immunoglobulin heavy-chain variable region, suggesting a more indolent disease course. Monoclonal B-cell lymphocytosis (MBL) has been identified recently as a likely precursor to CLL; it is found in the general population with increasing age and enriched in unaffected relatives of individuals with familial CLL. Studies of MBL as well as mouse models of CLL may lead to better understanding of early CLL pathogenesis that is relevant to familial predisposition. To date, the identification of genes that predispose to familial CLL has been slow, primarily due to the relatively few families available for study, the small size of those families and disease causation most likely by multiple genes that each confer smaller risks. In the coming years, the application of systematic genomics approaches to familial CLL should, hopefully, lead to the identification of novel loci involved in the disease.

\section{Keywords}

association; familial chronic lymphocytic leukemia; linkage; lymphocytosis; monoclonal B cell

\section{Inherited predisposition?}

Chronic lymphocytic leukemia (CLL), a B-cell lymphoproliferative disorder expected to affect 15,000 people this year in the USA alone, is one of the most common adult leukemias. Although the cause remains unknown, a family history of the disease is one of the best characterized risk factors. In fact, familial aggregation of the disease has been observed for decades, with multiple reports in the literature of families in whom the occurrence of CLL is greatly enriched with what appears to be almost Mendelian inheritance [1-3]. Approximately $12 \%$ of patients with CLL report a family history of a lymphoproliferative disorder (LPD), and 6-9\% have a relative who also has CLL [4-6]. Asians have significantly lower rates of CLL than CaucasianAmericans or Europeans and, importantly, those low rates are maintained after migration to the USA, suggesting that genetic rather than environmental factors are critical in these

\section{(c) 2008 Expert Reviews Ltd}

Financial \& competing interests disclosure

The author has no relevant affiliations or financial involvement with any organization or entity with a financial interest in or financial conflict with the subject matter or materials discussed in the manuscript. This includes employment, consultancies, honoraria, stock ownership or options, expert testimony, grants or patents received or pending, or royalties.

No writing assistance was utilized in the production of this manuscript. 
differences [7]. A study from the Utah Population Database has suggested that the populationattributable risk owing to inherited factors in CLL may be as high as 35\% [8], third behind prostate cancer at $57 \%$ and breast cancer at $39 \%$, indicating both that CLL is quite heritable and that inherited factors are critical in the causation of the disease and the population disease burden.

Not surprisingly, given these findings, population-based epidemiologic studies have consistently found that first-degree relatives of CLL patients have a three- to eight-times greater relative risk for the development of CLL. The most definitive study investigated familial aggregation of CLL and other LPDs among 5918 CLL probands and 11,778 matched controls identified from the Swedish Family Cancer Database [9]. In this study, the risk of CLL in firstdegree relatives of CLL probands was increased 7.5-times. Increased risks of Hodgkin's lymphomas (HL; 2.35-times) and non-Hodgkin's lymphomas (NHL; 1.45-times), but not multiple myeloma (MM), were also seen in family members of CLL probands. No effect of sex, type of relative or age at diagnosis of the proband was observed [9]. For CLL, relative risks derived from registry-based studies probably underestimate the actual risk because the frequency of CLL has been found to be underestimated in registry data, most likely due both to under-reporting of indolent cases diagnosed late in life and to reliance on tissue pathology and cancer treatment data as the primary sources of information [10-12].

The observation that other LPDs are sometimes seen in families with CLL is consistent, and increased relative risks of NHLs and HLs are frequently reported [13,14]. Clustering of other malignancies has not been as well studied. However, increased risks of CLL have been associated with breast cancer in mothers or sisters [14] and a family history of malignancy has been associated with increased risks of second, non-CLL malignancies in probands themselves $[15,16]$.

Overall, these data suggest that some genetic lesions may predispose to CLL alone, while others may increase the risk of CLL and other B-cell malignancies. This situation increases the difficulty of identifying genes because phenotypes are likely to overlap and the appropriate groupings of families for further study are unclear. The occurrence of solid tumors at a possibly increased rate in some of these families is likely to further complicate the picture. Additional work is still required to clarify how best to group families for further study of genetic susceptibilities.

\section{Familial versus sporadic CLL?}

A couple of studies have suggested that the median age of onset of CLL in those with a family history is approximately 10 years younger than in sporadic cases $[2,15]$. However, other studies, including Goldin's study using the Swedish Registry data, have found no significant difference in age of onset between familial and sporadic CLL [4,9]. Registry-based studies are less likely to be subject to selection bias than studies of families identified as at-risk, but nonetheless the data are conflicting.

A similar controversy has existed over whether anticipation occurs. Anticipation is the genetic phenomenon in which each successive generation develops the disease at a younger age than the previous generation. Anticipation has been most commonly observed in a number of neurodegenerative diseases whose molecular basis is triplet repeats that undergo expansion in the germline and, therefore, result in worsening disease in younger generations [17]. In the case of CLL, studies of families identified based on aggregation of CLL have suggested that the younger generation may be affected as much as $15-22$ years prior to their parents $[6,18$, 19]. The most systematic study, however, used the Swedish and Danish population-based registries and corrected for changes in disease incidence over time; this study found no evidence 
for anticipation in NHL, HL, CLL or MM [20]. In addition, no evidence for triplet repeat expansion as a possible molecular basis for familial CLL has been found [21].

Two studies have compared disease features between familial and sporadic CLL. Stage at diagnosis, need for treatment and 10-year overall survival have been reported to be similar [4]. These studies have found that women report a family history more commonly than men $[4,22]$, and the sex ratio of familial CLL is more equal than that of sporadic CLL. Sibling pairs affected with CLL have been reported to be more commonly of the same sex than expected by chance [23]. This phenomenon has also been reported in Hodgkin's disease, as well as sarcoidosis and multiple sclerosis [23]. Although not well understood, generally, this increased sex concordance among sibling pairs is thought to be due to inheritance involving the pseudoautosomal regions of the $\mathrm{X}$ and $\mathrm{Y}$ chromosomes or to shared environment [23].

In comparing biologic features of familial CLLs to sporadic CLLs, the most research has been devoted to the immunoglobulin heavy-chain variable genes $\left(I g V_{H}\right)$. V gene usage has been reported to be similar between familial and sporadic CLL, with $V H 3$ predominating, followed by $\mathrm{VHI}$ and $\mathrm{VH} 4$ [22,24-26]. The largest study addressing this question has just been published by Crowther et al. [22]. These authors compared V gene usage and mutation status among 327 cases of CLL from 214 families and 724 sporadic cases. Mutation status was not related to age at diagnosis or stage. Mutated CLL ( $<98 \%$ homologous to the closest germline $\mathrm{V}$ region) was observed in $68 \%$ of the familial cases, compared with $47 \%$ of the sporadic cases. Mutation status was correlated within families, among the 86 families with more than one affected individual studied [22]. One earlier study had also suggested that familial CLLs more commonly displayed somatic hypermutation than sporadic CLLs [24].

Other biologic features have not yet been as well studied in familial CLL. Telomere length appears to be correlated with mutation status, similar to sporadic CLL [27]. An abstract from the CLL Research Consortium compared 136 familial CLL patients and 814 sporadic patients and found no difference in $\zeta$-chain-associated protein kinase (ZAP)-70 expression, CD38 or CD23 expression or serum $\beta_{2}$-microglobulin levels [25]. Although deletion 13q and trisomy 12 have both been reported in familial CLL, and a question of increased frequency of deletion $13 q$ has been raised [28], no systematic evaluation of cytogenetics has yet been performed $[28,29]$. Two other observations that have been reported in familial CLL include higher serum levels of B-lymphocyte stimulator (BLyS) than in sporadic CLL [30,31] and a correlation between high expression of the chemokine receptor CXCR4 and improved survival [32].

Overall, these data suggest that the range of familial CLL is similar to that of sporadic CLL, but the detailed analyses of $\operatorname{Ig} V_{H}$ mutational status suggest that familial CLL may more often be low-risk disease [22,24]. Long-term follow-up studies will be required to confirm this suggestion.

\section{Monoclonal B-cell lymphocytosis: precursor condition?}

Low-level monoclonal B-cell populations have been identified in the peripheral blood of hematologically normal individuals within CLL families for over 15 years [33,34]. Similar Bcell populations were also identified in residents near hazardous waste sites in the early 1990s [33]. Follow-up studies of these residents have confirmed a prevalence of monoclonal B-cell lymphocytosis (MBL) of $0.6 \%$, with a suggestion of increased risk based on proximity to the hazardous waste site [35,36]. Studies of the general population have found that the frequency of MBL populations in hematologically normal outpatients increases with age: very rare under the age of 40 years; $2.1 \%$ in adults aged $40-59$ years; and 5-5.5\% in adults aged 60-89 years $[37,38]$. The most common phenotype on flow cytometry is CLL-like, namely positive for CD5, with dim CD20 [37,38]. However, an atypical CLL phenotype, positive for CD5 with 
bright CD20, and a non-CLL-like phenotype, which is negative for CD5 with bright CD20, have also both been described [37].

Monoclonal B-cell lymphocytosis appears to be more common in unaffected relatives in CLL families than in the general population. Two studies have detected these populations in 13.5$18 \%$ of first-degree relatives [34,39]. The relative risk varies with age, and is highest in younger adults, owing to the lower likelihood of MBL in the sporadic population at that age [40]. Whether the frequency of MBL is increased in relatives of sporadic CLL patients is not known.

The biology and natural history of MBL are only beginning to be elucidated. Deletion 13q and trisomy 12 have been identified in MBLs at similar frequencies to CLL, but the higher-risk abnormalities, deletions of $11 \mathrm{q}$ and $17 \mathrm{p}$, appear to be rare in MBL, recently found in only $9 \%$ of CLL-phenotype MBLs with lymphocytosis [41,42]. Of those studied by the UK Leeds group, $88-96 \%$ have shown mutated $\operatorname{Ig} V_{H}$ genes, with intraclonal heterogeneity similar to that in CLL [41-44]. The few MBLs that were unmutated progressed to CLL rapidly, but this was not terribly useful as a prognostic marker because of its rarity [42].

The most extensive data on natural history, again from the Leeds group, suggests that the majority of MBLs, at least of those identified in the general population, do not progress to CLL (58\%) [42]. This finding is similar to an earlier study of patients with mild lymphocytosis, eight out of 24 of whom progressed to CLL in 5 years [45]. The Leeds group defined MBL as an absolute B-cell count of less than $5.0 \times 10^{9} / 1$ with no lymphadenopathy and less than $30 \%$ CLL cells in the bone marrow if assessed [42]. This definition meant that the median absolute lymphocyte count for the patient population studied was $5.5 \times 10^{9} / \mathrm{l}$, which would mean that a significant fraction of these patients would be considered to have CLL using the 1996 diagnostic criteria [46] but not using the revised 2008 criteria [47]. Keeping that in mind, 42\% did show increasing absolute lymphocyte count, with $35 \%$ progressing to an absolute lymphocyte count of 10,000 at a median of 1.8 years of follow-up, and $12 \%$ progressing to 30,000 at a median of 4.1 years of follow-up [42]. The only significant predictor of progressive lymphocytosis was the B-cell count at presentation [41]. Of this group of MBLs, approximately $1 \%$ per year progressed to treatment for CLL, suggesting that MBL in the sporadic population may be a precursor condition to CLL, albeit one that does not frequently progress to CLL [41,42]. During follow-up for a median of 6.7 years in the most recently reported study, 62 out of 185 subjects died, but only four deaths were due to CLL [41]. A retrospective study of 46 MBLs, defined by the same criteria, found that the MBLs had a more indolent course than stage 0 or 1 CLLs, with a lower likelihood of needing treatment or transforming to a more aggressive disease [48]. These findings are also consistent with the model of MBL as a precursor condition for CLL.

These data from the sporadic population, namely outpatients referred to a hematology clinic, may not apply to familial MBL, however. The likelihood of progression among relatives with MBL from CLL families is not known and could be significantly higher, although progression to CLL was not reported in the National Cancer Institute (NCI) follow-up of familial MBL cases several years ago [49]. The emerging view is that MBL in at-risk individuals from CLL families may be a marker of the at-risk genotype and, if so, would indicate that the individual has at least a higher risk of developing clinical CLL. Therefore, MBL may provide a window into the earliest stages of CLL pathogenesis and an opportunity to identify additional gene carriers within families.

\section{Genetic models \& gene discovery}

The goal of characterization of familial CLL is to both understand any differences in disease patterns compared with sporadic CLL and to attempt to identify the genetic mechanisms that result in familial predisposition. Families such as 'Pedigree 14', in which CLL appears to be 
a highly penetrant phenotype [3], imply that at least some cases of familial CLL are probably due to genetic events that, in and of themselves, cause a very high risk of disease. Typically, such genes may be identified using linkage. However, the majority of familial CLL occurs in families with only two or three cases, sometimes in more distant relatives, suggestive of inheritance as a complex trait. This observation, plus the current difficulty with identifying genes or loci involved in familial CLL, implies that much of the genetic risk may be due to a wide variety of loci that each confer a small risk [2]. Typically, these genes are much harder to identify and may require large association studies involving thousands of affected individuals and controls. Are there any other novel approaches that could shed light on this problem? Other approaches that might be considered include the evaluation of candidate genes, use of mouse models to identify key genes to consider in human CLL or the use of novel genomic technologies to attempt to identify changes in gene copy number or gene expression in familial compared with sporadic CLL. We will consider these various approaches in turn.

\section{Linkage}

Linkage studies were hampered initially by small numbers of families, few affected individuals per family and a lack of high-density markers. The first study of 18 families by Goldin $e t$ al. used 359 microsatellite markers and did not find any genomic regions that were statistically significantly linked to disease inheritance [50]; a follow-up study with an additional 28 families identified 13q21 as a region of interest [51]. Unfortunately, a systematic search for mutations in protein-coding genes in that region found none [28]. The UK group used the Affymetrix $10 \mathrm{~K}$ single nucleotide polymorphism (SNP) array to perform a genome-wide scan of 105 families and found evidence to support linkage to $11 \mathrm{p} 11$, but this finding was also not statistically significant [52]. A combined analysis performed by the UK and US groups together used 206 families, with the Affymetrix 10K SNP array, and identified 2q21 as the most promising susceptibility locus, followed by $6 \mathrm{p} 22$ and $18 \mathrm{q} 21$ [52,53]. Possible candidate genes at these loci based on the biology of CLL include CXCR4 at 2q21, which has been associated with survival in familial CLL [32], and SMAD7 at 18q21, which may be involved in regulation of B-cell apoptosis [53]. Also of interest in this study is the identification of linkage to 6p22, the site of the MHC locus, which has previously been associated with familial CLL [54,55]. Analysis of these and other candidate genes at these loci is presumably ongoing but has not yet been published.

Recently, a genome-wide linkage analysis performed on a single family with six affected individuals including a father, four sons and a grandson, identified possible linkage to $9 \mathrm{q} 22$ with a nonparametric linkage score close to the maximum value possible given the small size of the pedigree [56,57]. The DAPKl gene is located in that region, which was found to be silenced in sporadic CLLs [57]. Further analysis found that the DAPKI haplotype found in affected individuals from this family showed reduced expression in fibroblasts, indicating that the altered expression was likely sequence based [57]. Sequencing of $400 \mathrm{~kb}$ of the affected and unaffected alleles eventually identified a SNP (c.1-6531A $>$ G) that was present in affected individuals and not in controls and was able to increase binding of the HOXB7 repressor, thereby decreasing DAPK1 expression [57]. Unfortunately, however, this allele appears to be very uncommon, found in only one out of the 263 sporadic CLLs examined and none out of the 75 additional familial CLLs examined [57]. Furthermore, sequencing of all DAPK exons and the region of the identified SNP in the latter 75 familial CLLs did not identify any alleles likely to be disease causing [57]. Thus, although the role of this DAPKI allele in CLL in this family is intriguing, the present evidence suggests that variation in $D A P K l$ is not likely to play a major role in the overall heritability of CLL. Nonetheless, the ubiquitous silencing of $D A P K 1$ in CLL may shed light on the underlying biology of the disease. 


\section{Association studies of candidate genes}

One attractive and more targeted approach to the identification of susceptibility genes is to select possible candidates based on the biology of the gene or the disease and then to look for mutations by sequencing or for associations with a particular SNP allele. For example, the $A T M$ gene is an excellent candidate gene because germline ATM alleles cause an inherited immunodeficiency disorder that is associated with increased rates of lymphoma, including, occasionally, CLL [58]; deletions of 11q22 or mutations of ATM are associated with poor-risk sporadic CLL $[59,60]$. However, investigations of ATM mutation in familial CLL have not supported a role for $A T M$ as a significant susceptibility locus. Although germline mutations have been identified in familial CLL patients, they have not segregated with the disease, nor has linkage to markers at 11q22 been found in small studies [61-63]. The HLA locus has also been a focus of interest, but small studies in families have not found linkage to its 6p21 locus [64]. Despite this, as discussed previously, the largest linkage study of 205 CLL families did recently find suggestive linkage to the HLA locus [53], which may mean that larger studies or family studies will be required to definitively resolve this question.

Similarly, many studies have investigated associations between CLL and one or several SNP alleles in a given candidate gene involved in B-cell biology. Typically, an initial study will report an association between a particular SNP allele and CLL in a fairly small number of patients, and then multiple subsequent studies will be unable to reproduce the finding. For example, $m c l-1$, a member of the $b c l-2$ family that is overexpressed in many CLLs, has two different promoter insertion alleles, one of six and one of 18 nucleotides, which were originally reported to be associated with CLL incidence, as well as disease progression [65]. However, subsequent reports found these alleles to be common in the population and not associated with CLL incidence [66-70]. Another example concerns the P2X7 receptor, a membrane ATP-gated ion channel involved in lymphocyte apoptosis. This gene contains a polymorphism that encodes a null allele that was associated with CLL risk in an initial study [71], but five subsequent studies were unable to confirm this association [72]. Similarly, the TNF- $\alpha 308$ promoter SNP, which has been associated with risk of NHL [73], was initially reported to be associated with CLL [74], but multiple subsequent studies and a pooled comparison failed to confirm these findings [75].

Not all findings of interest have yet been tested independently. For example, elevated serum levels of BLyS have been reported in 24 familial CLL patients compared with 46 sporadic CLL patients and 41 controls [31]. This finding was associated with a promoter polymorphism $(-871 \mathrm{C} / \mathrm{T})$ that increased gene expression and was found in $96 \%$ of familial CLLs compared with 70\% of sporadic CLLs and 76\% of controls [31]. A very recent study has found that sporadic CLLs show reduced BLyS (BAFF) levels compared with controls, and familial CLLs had BLyS levels that were similar to controls and, therefore, higher than sporadic CLLs [30]. The pattern of the altered BLyS levels is a little different between the two studies and the role of the polymorphism is unclear because it is very common in the general population. Therefore, additional work will be required to understand these findings. Other interesting findings not yet confirmed include an increased cumulative risk of CLL with increasing number of highrisk GST alleles [76] and a reported increase in CLL risk associated with a SNP in the ligandbinding site of TRAIL receptor 1 [77].

In summary, association studies with individual candidate genes have not yet proven fruitful in studying familial CLL, probably, in large part, because the number of patients and/or markers studied has been too small to give robust and reproducible results given the small increased risk of disease expected. 


\section{Pathway-association studies}

Rudd et al. recently took a larger scale approach to a candidate gene-association study, selecting 865 candidate genes likely to be involved in cancer. In total, 1467 coding nonsynonymous SNPs in 992 CLL patients and 2707 controls were genotyped [78]. Coding nonsynonymous SNPs were chosen to bias toward alleles that would be expected to alter protein function. Two SNPs in the ATM gene, F858L (odds ratio [OR]: 2.3) and P1054R (OR: 1.7), were most associated with CLL. In total, nine other SNPs in the DNA damage-response pathway were also implicated, including CHEK2 I157T (OR: 14.8), BRCA2 N372H (OR: 1.45) and BUB1 Q349R (OR: 1.42). This finding of multiple SNPs within the DNA damage pathway that were significantly associated with CLL was more than that expected by chance and more than that observed in other similar pathways and is, therefore, suggestive of involvement of this axis in the heritability of CLL [78]. Small effects such as these must be robust enough to be detected in this type of analysis, and the observed results, therefore, still need to be replicated in an independent cohort. Both Slager at the Mayo Clinic and Goldin at the NCI have reported that they are working on pathway-based association studies, in CLL in general or in their familial cases, and it will be interesting to see if similar results emerge from those studies, although the reported sample sizes are smaller (300-600 total) [29,79].

\section{Genomic alterations in CLL}

An entirely different approach to gene identification is to attempt to use genomic gains and losses identified in CLL, either sporadic or familial, to identify key causative genes. The minimal region of deletion at 13q14 in sporadic CLL is gene-poor and has been studied extensively. George Calin and Carlo Croce and colleagues have focused on this minimal region of deletion to identify a role of miR-16-1 and miR-15-a [80]. These miRNAs are believed to target $B c l-2$, such that $B c l-2$ would be overexpressed when they are deleted, as would be expected in CLL [81]. Two of the CLL patients studied were found to have germline mutations in the pri-microRNA precursor of miR-16-1 and miR-15-a; both patients had loss of heterozygosity at this locus within their CLL, suggesting function as a tumor-suppressor gene. Furthermore, one of these patients had a family history of CLL [82], although neither a detailed analysis of this family nor evaluation of other familial CLL cases for mutations in miR-16-1 and $m i R-15-a$ is yet available. Also in this same region of $13 \mathrm{q} 14$ is the $d L e u 2$ gene, which encodes a conserved long noncoding RNA of unknown function that is expressed in B cells but not CLL cells [83-85]. Ongoing work will be required to determine the role of miR-16-1 and $m i R-15-a$, or $d L e u 2$, if any, in familial CLL.

Another candidate gene found in the minimally deleted region at 13q14 is the ARLTS1 gene [86]. Calin et al. reported that a nonsense SNP in this gene, G446A (Trp149Stop), was associated with a family history of cancer or multiple personal cancers, and the SNP was found in two out of 17 familial CLL cases they investigated [86]. Sellick et al. then sought to replicate this finding and did not find an association between CLL and this SNP or five other nonsynonymous coding SNPs in ARLTS1, despite analyzing a cohort with a significant number of familial cases [87]. Similarly, $\mathrm{Ng}$ et al. found this SNP in two out of 31 familial CLL cases but the SNP did not segregate with CLL in these families, nor was it statistically overrepresented in families with LPDs compared with CEPH controls [88]. Thus, ARLTS1 does not appear to have a significant role in predisposition to familial CLL.

Systematic genome-wide approaches to the identification of chromosomal alterations have also been used. Comparative genomic hybridization has been used to screen the genome for areas of chromosomal gain or loss in 24 familial cases of CLL [89]. An average of seven abnormalities was found per case, most often on chromosomes 2, 11 and X. Although most changes were not concordant among family members, some were, or were present in multiple 
families; these included losses of Xp11.2-p21, 2p12-14 and 4q11-q21 [89]. Dok1, a candidate gene at $2 \mathrm{p} 13$, is a suppressor of cell proliferation and B-cell signaling that has not been found to have pathogenic mutations in a follow-up study of 140 familial CLL patients [90]. The significance of these chromosomal loci, therefore, still remains to be determined.

Newer high-resolution techniques using array-based comparative genome hybridization or SNP arrays are beginning to be applied to sporadic CLL and have not yet been reported in familial CLL. For example, in sporadic CLL, a recent report used 10K and 50K Affymetrix SNP arrays to identify a novel $3.5-\mathrm{Mb}$ gain at $2 \mathrm{p} 16$ in four patients with unmutated $I g V_{H}$ [91]. Candidate genes at this site include REL and BCL11A. In addition, because they used SNP arrays, this group was able to identify 24 large regions of loss of heterozygosity that were copy neutral [91] but that could eventually lead to interesting tumor-suppressor genes, possibly involved in familial CLL.

\section{Alternative novel approaches to gene identification Mouse models}

Historically, animal models have not been that fruitful in the study of CLL; however, in recent years, this appears to be be starting to change [92]. The New Zealand Black (NZB) mouse model arose de novo and develops B-cell expansion and autoimmune disease with eventual progression to CLL [93]. A recent genome-wide linkage analysis performed to map loci associated with LPD in these mice found three loci on chromosomes 14, 18 and 19 [94]. The region on mouse chromosome 14 is syntenic with 13q14 in humans and, in fact, a mutation was identified in the 3' flanking region of mouse mir-16-1 [94]. Levels of miR-16 were reduced in lymphoid tissue in these mice, consistent with the mutation being potentially pathogenic. Another group studying the same NZB model has found a locus on mouse chromosome 13 linked to marginal-zone hyperplasia [95]. Further characterization of this locus, as well as the loci on chromosomes 18 and 19, may generate additional leads for CLL-susceptibility genes, some of which may be relevant to familial CLL.

Transgenic mice may also prove helpful in elucidating the pathogenesis of CLL. In particular, the TCL1 oncogene, which was originally identified at the site of chromosomal rearrangements in mature T-cell leukemias [96], is an activator of the PI3K/Akt pathway [97,98] and is overexpressed in CLLs with unmutated $I g V_{H}$ and ZAP70 positivity [99]. Transgenic mice that express TCL1 under the control of the IgH-E $\mu$ enhancer develop an expansion of $\mathrm{CD}^{+} \mathrm{B}$ cells starting as early as 2 months of age, with progression to a frank LPD that is similar to aggressive CLL by 10-20 months [100]. These mice provide both a model for testing novel therapies [101] and an opportunity to explore the molecular changes present at a very early stage of disease, which may provide insight into the origins of human CLL.

Other transgenic models may also provide insight into CLL. Overexpression of Bcl-2 with a construct similar to $t(14 ; 18)$ in human follicular lymphoma is not sufficient to induce malignancy in mice [102]. Similarly, transgenic mice that express a dominant negative form of TRAF2, which normally binds to TNF receptors and activates JNK and nuclear factor- $\mathrm{\kappa B}$, develop increased B cells, but no frank malignancy [103]. However, the double transgenics, TRAF2DN/Bcl-2, nearly universally develop splenomegaly and B-cell leukemia similar to CLL [104].

Finally, transgenic mice that express APRIL, a TNF family-member related to BLyS/BAFF, from a T-cell specific $L C K$ promoter have elevated serum levels of APRIL and develop a progressive expansion of $\mathrm{CD}^{+} \mathrm{B}$ cells in approximately half the animals [105]. These mice have a significantly milder phenotype than the two described earlier but, nonetheless, have the potential to provide insight into the pathogenesis of CLL. 


\section{Gene-expression profiling}

Gene-expression profiling has a couple of possible roles in the effort to discover predisposition loci in CLL. First, an expression profile could prove very useful in assessing the functional significance of genomic gains or losses determined through array comparative genomic hybridization (CGH) or SNP arrays. Second, expression profiling could be used for discovery to identify differences in expression patterns between familial and sporadic CLL. In the same way, genome-wide scans to compare methylation patterns in familial and sporadic CLL could be considered [106]. Using either of these techniques in this way assumes that familial and sporadic CLLs have detectable biologic differences that remain even after the disease reaches its full-blown form, which is presently an unproven hypothesis. Current data suggest that, at least at a crude level of analysis, familial CLLs are similar to sporadic CLLs biologically. However, if the initiating events can diverge, a highly detailed analysis, such as expression profiling or methylation scanning, may be able to reveal clues to pathogenesis; only ongoing and future work will determine this.

\section{Whole-genome-association studies}

As discussed previously, the data thus far suggest that CLL is a genetically heterogeneous disease, with many genes each conferring small relative risks. Therefore, if the biology of mouse models and genomics applied to MBL or familial CLL fail to point us toward probable predisposition genes, the field will most likely need to rely on whole-genome-association studies. Whole-genome-association studies scan through the genome using 100,000-1,000,000 SNPs in an effort to cover as much genomic variation as possible and to identify loci associated with small increases in disease risk [107]. Recent whole-genome-association studies have reported significant findings in colon [108-111], breast [112], prostate [113-116] and lung cancers [117], among others. These studies, which have only become feasible recently, generally require thousands of cases and controls, although employing clearly familial cases may enhance detection $[108,112]$. Whole-genome- association studies are in progress in CLL and the results are eagerly awaited.

\section{Expert commentary}

Familial risk in CLL is now well established, even though much work remains to be carried out to clarify the detailed relationship between CLL occurring in families and other LPDs and solid tumors in those families. Preliminary biological characterization of familial CLL suggests that disease features are largely similar to sporadic CLL, with possible skewing toward mutated $I g V_{H}$, suggesting more indolent disease. The recent characterization of MBL as a likely precursor condition and marker of genetic susceptibility will allow enhanced study of the very early phases of the disease, as well as better definition of which individuals in a family are considered affected. The availability of MBL samples should enhance our ability to study early disease pathogenesis.

Gene identification has, thus far, been extremely limited, primarily owing to relatively few available families with multiple living affected individuals. The difficulty in identifying genes to date confirms that CLL is likely to be genetically heterogeneous, with multiple genes contributing small relative risks. So far, the best candidate gene identified is DAPK, found by linkage from a family with many affected individuals but unlikely to be responsible for a large fraction of familial CLL based on present data. Individual candidate gene studies have largely been underpowered and have come up empty, but larger-scale pathway-association studies have implicated DNA repair mechanisms in the pathogenesis of CLL.

Currently, much excitement focuses on the application of genomic technologies, including array CGH, SNP arrays and gene-expression profiling to CLL, both familial and sporadic. 
Recent mouse models hold promise for elucidating early phases of CLL pathogenesis. Ultimately, whole-genome association studies with large numbers of CLL cases and controls will probably be required to identify loci with low relative risks of disease.

\section{Five-year view}

Over the next 5 years, better biologic characterization of familial CLLs, as well as MBLs, together with the study of mouse models of CLL, should enhance our understanding of the initiating events in CLL pathogenesis. Results from genomic studies coupled with geneexpression profiling will provide additional insight into genetic alterations associated with CLL. As with other cancers, in the next few years, whole-genome-association studies will, hopefully, identify loci associated with the development of CLL. The field of familial CLL may, therefore, be on the brink of significant breakthroughs made possible by high-throughput technologies. Following the identification of genetic loci, however, will be the difficult detailed characterization required to understand how the locus contributes to the disease. Making this connection can often be difficult with the state of current knowledge but, ultimately, this connection is what will be required to enhance our understanding of the pathogenesis of CLL.

\section{Key issues}

- Chronic lymphocytic leukemia (CLL) remains of unknown cause; however, family history is the strongest risk factor identified.

- First-degree relatives of individuals with CLL have a three- to eightfold increased risk of CLL and smaller but still increased risks of Hodgkin's or non-Hodgkin's lymphomas.

- Familial CLL appears similar to sporadic CLL in clinical features but has been reported to show more frequent somatic hypermutation of the immunoglobulin heavy-chain variable region.

- Monoclonal B-cell lymphocytosis (MBL) is the presence of a monoclonal B-cell population of less than 5000 cells $/ \mathrm{mm}^{3}$ in the peripheral blood of individuals who are otherwise hematologically normal and have no signs or symptoms of CLL or another lymphoproliferative disorder.

- MBL is more common in unaffected individuals from families with familial CLL than in the general population and may represent a precursor condition. MBL is similar to good-prognosis CLL in terms of biologic features.

- Efforts to identify causative genes in familial CLL using linkage or candidate geneassociation studies have proved difficult to date, suggesting that CLL is genetically heterogeneous, with multiple loci involved.

- A single nucleotide polymorphism in the regulatory region of DAP kinase has been associated with familial CLL in a single family but is not likely to be involved in most familial CLL.

- Mouse models of CLL and high-throughput genomic technologies allowing detailed characterization of copy number changes and loss of heterozygosity may provide greater insight into pathogenesis in the near future.

- Whole-genome-association studies have proven fruitful for identifying susceptibility loci in other malignancies and, hopefully, will also prove useful in CLL. Then, the difficult work of understanding the biological connection between the locus and the disease can begin. 


\section{References}

Papers of special note have been highlighted as:

- of interest

•• of considerable interest

1. Caporaso N, Marti GE, Goldin L. Perspectives on familial chronic lymphocytic leukemia: genes and the environment. Semin. Hematol 2004;41(3):201-206. [PubMed: 15269880]

2. Sellick GS, Catovsky D, Houlston RS. Familial chronic lymphocytic leukemia. Semin. Oncol 2006;33 (2):195-201. [PubMed: 16616066]

3. Jonsson V, Houlston RS, Catovsky D, et al. CLL family 'Pedigree 14' revisited: 1947-2004. Leukemia 2005;19(6):1025-1028. [PubMed: 15800670]

4. Mauro FR, Giammartini E, Gentile M, et al. Clinical features and outcome of familial chronic lymphocytic leukemia. Haematologica 2006;91(8):1117-1120. [PubMed: 16885053]

5. Capalbo S, Trerotoli P, Ciancio A, et al. Increased risk of lymphoproliferative disorders in relatives of patients with B-cell chronic lymphocytic leukemia: relevance of the degree of familial linkage. Eur. J. Haematol 2000;65(2):114-117. [PubMed: 10966171]

6. Yuille MR, Houlston RS, Catovsky D. Anticipation in familial chronic lymphocytic leukaemia. Leukemia 1998;12:1696-1698. [PubMed: 9823943]

7. Pang JWY, Cook LS, Schwartz SM, Weiss NS. Incidence of leukemia in Asian migrants to the United States and their descendants. Cancer Causes Cont 2002;13:791-795.

8. Kerber RA, O'Brien E. A cohort study of cancer risk in relation to family histories of cancer in the Utah population database. Cancer 2005;103(9):1906-1915. [PubMed: 15779016]

9. Goldin LR, Pfeiffer RM, Li X, Hemminki K. Familial risk of lymphoproliferative tumors in families of patients with chronic lymphocytic leukemia: results from the Swedish Family-Cancer Database. Blood 2004;104(6):1850-1854.1854 [PubMed: 15161669] • Provides the best estimates of familial risks of chronic lymphocytic leukemia (CLL), non-Hodgkin's lymphoma and Hodgkin's lymphoma in families of those with CLL.

10. Dores G, Anderson W, Curtis R, et al. Chronic lymphocytic leukemia and small lymphocytic lymphoma: overview of the descriptive epidemiology. Br. J. Haematol 2007;139:809-819. [PubMed: 17941952]

11. Turesson I, Linet M, Bjorkholm M, et al. Ascertainment and diagnostic accuracy for hematopoietic lymphoproliferative malignancies in Sweden 1964-2003. Int.J. Cancer 2007;121:2260-2266. [PubMed: 17583571]

12. Zent CS, Kyasa MJ, Evans R, Schichman SA. Chronic lymphocytic leukemia incidence is substantially higher than estimated from tumor registry data. Cancer 2001;92(5):1325-1330. [PubMed: 11571749]

13. Chang ET, Smedby KE, Hjalgrim H, et al. Family history of hematopoietic malignancy and risk of lymphoma. J. Natl Cancer Inst 2005;97(19):1466-1474. [PubMed: 16204696]

14. Pottern LM, Linet MS, Blair A, et al. Familial cancers associated with subtypes of leukemia and nonHodgkin's lymphoma. Leukemia Res 1991;15(5):305-314. [PubMed: 2046383]

15. Ishibe N, Sgambati MT, Fontaine L, et al. Clinical characteristics of familial B CLL in the National Cancer Institute Familial Registry. Leuk. Lymphoma 2001;42(1-2):99-108. [PubMed: 11699227]

16. Landgren O, Pfeiffer RM, Stewart L, et al. Risk of second malignant neoplasms among lymphoma patients with a family history of cancer. Intl J. Cancer 2006;120:1099-1102.

17. Di Prospero NA, Fischbeck KH. Therapeutics development for triplet repeat expansion diseases. Nat. Rev. Genet 2005;6(10):756-765. [PubMed: 16205715]

18. Goldin LR, Sgambati M, Marti GE, et al. Anticipation in familial chronic lymphocytic leukemia. Am. J. Hum. Genet 1999;65:265-269. [PubMed: 10364544]

19. Horwitz M, Goode EL, Jarvik GP. Anticipation in familial leukemia. Am.J. Hum. Genet 1996;59(5): 990-998. [PubMed: 8900225] 
20. Daugherty SE, Pfeiffer RM, Mellemkjaer L, Hemminki K, Goldin LR. No evidence for anticipation in lymphoproliferative tumors in population-based samples. Cancer Epidemiol. Biomarkers Prev 2005;14(5):1245-1250. [PubMed: 15894680]

21. Benzow KA, Koob MD, Condie A, et al. Instability of CAG-trinucleotide repeats in chronic lymphocytic leukemia. Leuk. Lymphoma 2002;43(10):1987-1990. [PubMed: 12481897]

22. Crowther D, Wild R, Sellick G, et al. Insight into the pathogenesis of chronic lymphocytic leukemia (CLL) through analysis of $I g V_{H}$ gene usage and mutation status in familial CLL. Blood 2008;111 (12):5691-5693.5693 [PubMed: 18424666] - First detailed biological characterization of an aspect of familial CLL in comparison to sporadic CLL, showing a higher frequency of mutated $I_{g} V_{H}$ among familial CLLs.

23. Sellick GS, Allinson R, Matutes E, Catovsky D, Houlston RS. Increased sex concordance of sibling pairs with chronic lymphocytic leukemia. Leukemia 2004;18(6):1162-1163. [PubMed: 15085160]

24. Pritsch O, Troussard X, Magnac C, et al. VH gene usage by family members affected with chronic lymphocytic leukaemia. Br.J. Haematol 1999;107(3):616-624. [PubMed: 10583268]

25. Rassenti LZ, Toy TL, Huynh L, et al. High similarity between familial and sporadic cases of chronic lymphocytic leukemia. Blood 2003;102:670a.

26. Sakai A, Marti GE, Caporaso N, et al. Analysis of expressed immunoglobulin heavy chain genes in familial B-CLL. Blood 2000;95(4):1413-1419. [PubMed: 10666219]

27. Ishibe N, Prieto D, Hosack DA, et al. Telomere length and heavy-chain mutation status in familial chronic lymphocytic leukemia. Leuk. Res 2002;26(9):791-794. [PubMed: 12127552]

28. Ng D, Toure O, Wei MH, et al. Identification of a novel chromosome region, 13q21.33-q22.2, for susceptibility genes in familial chronic lymphocytic leukemia. Blood 2007;109(3):916-925. [PubMed: 17047154]

29. Goldin LR, Caporaso NE. Family studies in chronic lymphocytic leukemia and other lymphoproliferative tumors. Br.J. Haematol 2007;139:774-779. [PubMed: 18021091]

30. Molica S, Digiesi G, Mauro F, et al. Increased serum BAFF (B-cell activating factor of the TNF family) level is a peculiar feature associated with familial chronic lymphocytic leukemia. Leuk. Res. 2008(Epub ahead of print)

31. Novak AJ, Grote DM, Ziesmer SC, et al. Elevated serum B-lymphocyte stimulator levels in patients with familial lymphoproliferative disorders. J. Clin.Oncol 2006;24(6):983-987. [PubMed: 16432079]

32. Ishibe N, Albitar M, Jilani IB, et al. CXCR4 expression is associated with survival in familial chronic lymphocytic leukemia but CD38 expression is not. Blood 2002;100(1):1100-1101. [PubMed: 12150154]

33. Marti GE, Abbasi F, Raveche E, et al. Overview of monoclonal B-cell lymphocytosis. Br. J. Haematol 2007;139:701-708. [PubMed: 18021084]

34. Marti GE, Carter P, Abbasi F, et al. B-cell monoclonal lymphocytosis and B-cell abnormalities in the setting of familial B-cell chronic lymphocytic leukemia. Cytometry B Clin. Cytom 2003;52(1):112. [PubMed: 12599176]

35. Vogt RF, Shim YK, Middleton DC, et al. Monoclonal B-cell lymphocytosis as a biomarker in environmental health studies. Br. J. Haematol 2007;139(5):690-700. [PubMed: 18021083]

36. Shim YK, Vogt RF, Middleton D, et al. Prevalence and natural history of monoclonal and polyclonal B-cell lymphocytosis in a residential adult population. Cytometry B Clin. Cytom 2007;72(5):344353. [PubMed: 17266153]

37. Ghia P, Prato G, Scielzo C, et al. Monoclonal $\mathrm{CD}^{+}$and $\mathrm{CD} 5^{-}$B-lymphocyte expansions are frequent in the peripheral blood of the elderly. Blood 2004;103(6):2337-2342.2342 [PubMed: 14630808] • Characterizes monoclonal B-cell lymphocytosis (MBL).

38. Rawstron AC, Green MJ, Kuzmicki A, et al. Monoclonal B lymphocytes with the characteristics of "indolent" chronic lymphocytic leukemia are present in $3.5 \%$ of adults with normal blood counts. Blood 2002;100(2):635-639.639 [PubMed: 12091358] • Characterizes MBL.

39. Rawstron AC, Yuille MR, Fuller J, et al. Inherited predisposition to CLL is detectable as subclinical monoclonal B-lymphocyte expansion. Blood 2002;100(7):2289-2290.2290 [PubMed: 12239136] • Characterizes MBL. 
40. de Tute R, Yuille M, Catovsky D, et al. Monoclonal B-cell lymphocytosis (MBL) in CLL families: substantial increase in relative risk for young adults. Leukemia 2006;20(4):728-729. [PubMed: 16437141]

41. Rawstron AC, Bennett FL, O'Connor SJ, et al. Monoclonal B-cell lymphocytosis and chronic lymphocytic leukemia. N.Engl. J. Med 2008;359(6):575-583.583 [PubMed: 18687638] •• Demonstrates that MBL is a precursor condition for CLL and defines the rate of progression.

42. Rawstron AC, Bennett F, Hillmen P. The biological and clinical relationship between $\mathrm{CD}^{+} 23^{+}$ monoclonal B cell lymphocytosis and chronic lymphocytic leukemia. Br. J. Haematol 2007;139:724729.729 [PubMed: 18021087 ] $\bullet$ Demonstrates that MBL is a precursor condition for CLL and defines the rate of progression.

43. Rawstron AC, Fenton JAL, Plummer M, et al. Monoclonal B cell lymphocytosis (MBL) and CLL show intraclonal variation: cases classified as "unmutated" have the greatest clonal diversity. Blood 2006;108(11):13a.

44. Bennett FL, Fenton JAL, O'Connor SJM, Hillmen P, Rawstron AC. Disease progression in monoclonal B-cell lymphocytosis is independent of VH mutation status. Blood 2006;108(11):13a.

45. Faguet GB, Agee JF, Marti GE. Clone emergence and evolution in chronic lymphocytic leukemia: characterization of clinical, laboratory, and immunophenotypic profiles of 25 patients. Leuk. Lymphoma 1992;6:345-356.

46. Cheson BD, Bennett JM, Grever M, et al. National Cancer Institute-sponsored Working Group guidelines for chronic lymphocytic leukemia: revised guidelines for diagnosis and treatment. Blood 1996;87(12):4990-4997. [PubMed: 8652811]

47. Hallek M, Cheson BD, Catovsky D, et al. Guidelines for the diagnosis and treatment of chronic lymphocytic leukemia: a report from the International Workshop on Chronic Lymphocytic Leukemia (IWCLL) updating the National Cancer Institute-Working Group (NCI-WG) 1996 guidelines. Blood 2008;111(12):5446-5456.5456 [PubMed: 18216293] • New guidelines for diagnosis, staging and response evaluation in CLL.

48. Fung SS, Hillier KL, Leger CS, et al. Clinical progression and outcome of patients with monoclonal B-cell lymphocytosis. Leuk. Lymphoma 2007;48(6):1087-1091. [PubMed: 17577771]

49. Marti GE, Rawstron AC, Ghia P, et al. Diagnostic criteria for monoclonal B-cell lymphocytosis. Br. J. Haematol 2005;130:325-332. [PubMed: 16042682]

50. Goldin LR, Ishibe N, Sgambati M, et al. A genome scan of 18 families with chronic lymphocytic leukaemia. Br. J. Haematol 2003;121(6):866-873. [PubMed: 12786797]

51. Ng D, Marti GE, Fontaine L, et al. High-density mapping and follow-up studies on chromosomal regions $1,3,6,12,13$ and 17 in 28 families with chronic lymphocytic leukaemia. Br. J. Haematol 2006;133(1):59-61. [PubMed: 16512829]

52. Sellick GS, Webb EL, Allinson R, et al. A high-density SNP genomewide linkage scan for chronic lymphocytic leukemia-susceptibility loci. Am. J. Hum. Genet 2005;77(3):20-429.

53. Sellick GS, Goldin LR, Wild RW, et al. A high-density SNP genome-wide linkage search of 206 families identifies susceptibility loci for chronic lymphocytic leukemia. Blood 2007;110(9):33263333.3333 [PubMed: 17687107] • Largest linkage study in familial CLL to date.

54. Theodorou I, Abel L, Mauro F, et al. High occurence of DRB1 11 in chronic lymphocytic leukaemia families. Br. J. Haematol 2002;119(3):713-715. [PubMed: 12437649]

55. Machulla HKG, Mueller LP, Schaaf A, et al. Association of chronic lymphocytic leukemia with specific alleles of the HLA-DR4:DR53:DQ8 haplotype in German patients. Int. J. Cancer 2001;92:203-207. [PubMed: 11291046]

56. Plass C, Byrd JC, Raval A, Tanner SM, de la Chapelle A. Molecular profiling of chronic lymphocytic leukemia: genetics meets epigenetics to identify predisposing genes. Br. J. Haematol 2007;139:744752. [PubMed: 17961188]

57. Raval A, Tanner SM, Byrd JC, et al. Downregulation of death-associated protein kinase 1 (DAPK1) in chronic lymphocytic leukemia. Cell 2007;129(5):879-890.890 [PubMed: 17540169] •• Identification of the involvement of DAPK1 in one large pedigree of familial CLL.

58. Swift M, Reitnauer PJ, Morrell D, Chase CL. Breast and other cancers in families with ataxiatelangiectasia. N. Engl. J. Med 1987;316(21):1289-1294. [PubMed: 3574400] 
59. Dohner H, Stilgenbauer S, Benner A, et al. Genomic aberrations and survival in chronic lymphocytic leukemia. N. Engl. J. Med 2000;343(26):1910-1916. [PubMed: 11136261]

60. Austen B, Skowronska A, Baker C, et al. Mutation status of the residual ATM allele is an important determinant of the cellular response to chemotherapy and survival in patients with chronic lymphocytic leukemia containing an 11q deletion. J. Clin. Oncol 2007;25(34):5448-5457. [PubMed: 17968022]

61. Bevan S, Catovsky D, Marossy A, et al. Linkage analysis for ATM in familial B cell chronic lymphocytic leukaemia. Leukemia 1999;13(10):1497-1500. [PubMed: 10516748]

62. Ishibe N, Goldin LR, Caporaso NE, et al. ATM mutations and protein expression are not associated with familial B-CLL cases. Leuk. Res 2003;27(10):973-975. [PubMed: 12860021]

63. Yuille MR, Condie A, Hudson CD, et al. ATM mutations are rare in familial chronic lymphocytic leukemia. Blood 2002;100(2):603-609. [PubMed: 12091354]

64. Bevan S, Catovsky D, Matutes E, et al. Linkage analysis for major histocompatibility complex-related genetic susceptibility in familial chronic lymphocytic leukemia. Blood 2000;96(12):3982-3984. [PubMed: 11090088]

65. Moshynska O, Sankaran K, Pahwa P, Saxena A. Prognostic significance of a short sequence insertion in the MCL-1 promoter in chronic lymphocytic leukemia. J. Natl Cancer Inst 2004;96(9):673-682. [PubMed: 15126604]

66. Dicker F, Rauhut S, Kohlmann A, et al. Re: prognostic significance of a short sequence insertion in the MCL-1 promoter in chronic lymphocytic leukemia. J. Natl Cancer Inst 2005;97(14):1092-1093. [PubMed: 16030312] author reply 1093-1095

67. Freeman SN, Bepler G, Haura E, Sutphen R, Cress WD. Re: prognostic significance of a short sequence insertion in the $M C L-1$ promoter in chronic lymphocytic leukemia. J. Natl Cancer Inst 2005;97(14):1088-1089. [PubMed: 16030308]author reply 1093-1095

68. Vargas RL, Felgar RE, Rothberg PG. Re: prognostic significance of a short sequence insertion in the MCL-1 promoter in chronic lymphocytic leukemia. J. Natl Cancer Inst 2005;97(14):1089-1090. [PubMed: 16030309] author reply 1093-1095

69. Iglesias-Serret D, Coll-Mulet L, Santidrian AF, et al. Re: prognostic significance of a short sequence insertion in the $M C L-1$ promoter in chronic lymphocytic leukemia. J. Natl Cancer Inst 2005;97(14): 1090-1091. [PubMed: 16030310]author reply 1093-1095

70. Nenning UC, Eckert C, Wellmann S, et al. Re: prognostic significance of a short sequence insertion in the $M C L-1$ promoter in chronic lymphocytic leukemia. J. Natl Cancer Inst 2005;97(14):10911092. [PubMed: 16030311] author reply 1093-1095

71. Wiley JS, Dao-Ung LP, Gu BJ, et al. A loss-of-function polymorphic mutation in the cytolytic P2X7 receptor gene and chronic lymphocytic leukaemia: a molecular study. Lancet 2002;359(9312):11141119. [PubMed: 11943260]

72. Sellick GS, Rudd M, Eve P, et al. The P2X7 receptor gene A1513C polymorphism does not contribute to risk of familial or sporadic chronic lymphocytic leukemia. Cancer Epidemiol. Biomarkers Prev 2004;13(6):1065-1067. [PubMed: 15184265]

73. Rothman N, Skibola CF, Wang SS, et al. Genetic variation in TNF and IL10 and risk of non-Hodgkin lymphoma: a report from the InterLymph Consortium. Lancet Oncol 2006;7(1):27-38. [PubMed: 16389181]

74. Demeter J, Porzsolt F, Ramisch S, et al. Polymorphism of the tumor necrosis factor- $\alpha$ and lymphotoxin- $\alpha$ genes in chronic lymphocytic leukemia. Br. J. Haematol 1997;97:107-112. [PubMed: 9136948]

75. Bogunia-Kubik K, Mazur G, Urbanowicz I, et al. Lack of association between the TNF- $\alpha$ promoter gene polymorphism and susceptibility to B-cell chronic lymphocytic leukemia. Int. J. Immunogenet 2006;33:21-24. [PubMed: 16426238]

76. Yuille M, Condie A, Hudson C, et al. Relationship between glutathione S-transferase M1, T1, and P1 polymorphisms and chronic lymphocytic leukemia. Blood 2002;99(11):4216-4218. [PubMed: 12010828]

77. Wolf S, Mertens D, Pscherer A, et al. Ala228 variant of trail receptor 1 affecting the ligand binding site is associated with chronic lymphocytic leukemia, mantle cell lymphoma, prostate cancer, head 
and neck squamous cell carcinoma and bladder cancer. Int. J. Cancer 2006;118(7):1831-1835. [PubMed: 16217763]

78. Rudd MF, Sellick GS, Webb EL, Catovsky D, Houlston RS. Variants in the ATM-BRCA2-CHEK2 axis predispose to chronic lymphocytic leukemia. Blood 2006;108(2):638-644. [PubMed: 16574953]

79. Slager SL, Kay NE, Fredericksen ZS, et al. Susceptibility genes and B-chronic lymphocytic leukaemia. Br. J. Haematol 2007;139:762-771. [PubMed: 18021089]

80. Calin GA, Dumitru CD, Shimizu M, et al. Frequent deletions and down-regulation of micro- RNA genes miR15 and miR16 at 13q14 in chronic lymphocytic leukemia. Proc. Natl Acad. Sci. USA 2002;99(24):15524-15529.15529 [PubMed: 12434020] • Identification of the role of miR15 and miR16 in CLL.

81. Cimmino A, Calin GA, Fabbri M, et al. miR-15 and miR-16 induce apoptosis by targeting BCL2. Proc. Natl Acad. Sci. USA 2005;102(39):13944-13949. [PubMed: 16166262]

82. Calin GA, Ferracin M, Cimmino A, et al. A microRNA signature associated with prognosis and progression in chronic lymphocytic leukemia. N. Engl. J. Med 2005;353(17):1793-1801. [PubMed: 16251535]

83. Dalla-Favera R, Siegel R, Lia M, Klein U. New insights into the pathogenesis of CLL by in vitro and in vivo models. Leuk. Lymph 2007;48:S7.

84. Migliazza A, Bosch F, Komatsu H, et al. Nucleotide sequence, transcription map, and mutation analysis of the 13q14 chromosomal region deleted in B-cell chronic lymphocytic leukemia. Blood 2001;97(7):2098-2104. [PubMed: 11264177]

85. Tyybakinoja A, Vilpo J, Knuutila S. High-resolution oligonucleotide array-CGH pinpoints genes involved in cryptic losses in chronic lymphocytic leukemia. Cytogenet. Genome Res 2007;118(1): 8-12. [PubMed: 17901694]

86. Calin GA, Trapasso F, Shimizu M, et al. Familial cancer associated with a polymorphism in ARLTS1. N. Engl. J. Med 2005;352(16):1667-1676. [PubMed: 15843669]

87. Sellick GS, Houlston RS. Relationship between ARLTS1 polymorphisms and risk of chronic lymphocytic leukemia. Leuk. Res 2006;30(12):1573-1576. [PubMed: 16581122]

88. Ng D, Toure O, Fontaine L, et al. No association of ARLTS1 polymorphisms and risk for familial chronic lymphocytic leukemia. Br. J. Haematol 2007;137:170-175. [PubMed: 17391498]

89. Summersgill B, Thornton $\mathrm{P}$, Atkinson $\mathrm{S}$, et al. Chromosomal imbalances in familial chronic lymphocytic leukaemia: a comparative genomic hybridisation analysis. Leukemia 2002;16(7):12291232. [PubMed: 12094247]

90. Sellick GS, Coleman RJ, Talaban RV, et al. Germline mutations in Dokl do not predispose to chronic lymphocytic leukemia. Leuk. Res 2005;29(1):59-61. [PubMed: 15541476]

91. Pfeifer D, Pantic M, Skatulla I, et al. Genome-wide analysis of DNA copy number changes and LOH in CLL using high-density SNP arrays. Blood 2007;109(3):1202-1210. [PubMed: 17053054]

92. Scaglione BJ, Salerno E, Balan M, et al. Murine models of chronic lymphocytic leukaemia: role of microRNA-16 in the New Zealand Black mouse model. Br. J. Haematol 2007;139(5):645-657. [PubMed: 17941951]

93. Phillips JA, Mehta K, Fernandez C, Raveche ES. The NZB mouse as a model for chronic lymphocytic leukemia. Cancer Res 1992;52(2):437-443. [PubMed: 1370214]

94. Raveche ES, Salerno E, Scaglione BJ, et al. Abnormal microRNA-16 locus with synteny to human 13q14 linked to CLL in NZB mice. Blood 2007;109(12):5079-5086. [PubMed: 17351108]

95. Wither JE, Loh C, Lajoie G, et al. Colocalization of expansion of the splenic marginal zone population with abnormal B cell activation and autoantibody production in B6 mice with an introgressed New Zealand Black chromosome 13 interval. J. Immunol 2005;175(7):4309-4319. [PubMed: 16177071]

96. Virgilio L, Narducci MG, Isobe M, et al. Identification of the TCL1 gene involved in T-cell malignancies. Proc. Natl Acad. Sci. USA 1994;91(26):12530-12534. [PubMed: 7809072]

97. Laine J, Kunstle G, Obata T, Sha M, Noguchi M. The protooncogene TCL1 is an Akt kinase coactivator. Mol Cell 2000;6(2):395-407. [PubMed: 10983986]

98. Pekarsky Y, Koval A, Hallas C, et al. Tcl1 enhances Akt kinase activity and mediates its nuclear translocation. Proc. Natl Acad. Sci. USA 2000;97(7):3028-3033. [PubMed: 10716693] 
99. Herling M, Patel KA, Khalili J. TCL1 shows a regulated expression pattern in chronic lymphocytic leukemia that correlates with molecular subtypes and proliferative state. Leukemia 2006;20(2):280285. [PubMed: 16341048]

100. Bichi R, Shinton SA, Martin ES, et al. Human chronic lymphocytic leukemia modeled in mouse by targeted TCL1 expression. Proc. Natl Acad. Sci. USA 2002;99(10):6955-6960. [PubMed: 12011454]

101. Johnson AJ, Lucas DM, Muthusamy N, et al. Characterization of the TCL-1 transgenic mouse as a preclinical drug development tool for human chronic lymphocytic leukemia. Blood 2006;108(4): 1334-1338. [PubMed: 16670263]

102. Katsumata M, Siegel RM, Louie DC, et al. Differential effects of Bcl-2 on T and B cells in transgenic mice. Proc. Natl Acad. Sci. USA 1992;89(23):11376-11380. [PubMed: 1454823]

103. Lee SY, Reichlin A, Santana A, et al. TRAF2 is essential for JNK but not NF- $\mathrm{B}$ activation and regulates lymphocyte proliferation and survival. Immunity 1997;7(5):703-713. [PubMed: 9390693]

104. Zapata JM, Krajewska M, Morse HC 3rd, Choi Y, Reed JC. TNF receptor-associated factor (TRAF) domain and Bcl-2 cooperate to induce small B cell lymphoma/chronic lymphocytic leukemia in transgenic mice. Proc. Natl Acad. Sci. USA 2004;101(47):16600-16605. [PubMed: 15545599]

105. Planelles L, Carvalho-Pinto CE, Hardenberg G, et al. APRIL promotes B-1 cell-associated neoplasm. Cancer Cell 2004;6(4):399-408. [PubMed: 15488762]

106. Rush LJ, Raval A, Funchain P, et al. Epigenetic profiling in chronic lymphocytic leukemia reveals novel methylation targets. Cancer Res 2004;64(7):2424-2433. [PubMed: 15059895]

107. Barrett JC, Cardon LR. Evaluating coverage of genome-wide association studies. Nat. Genet 2006;38 (6):659-662.662 [PubMed: 16715099] - Illustrates the recent use of genome-wide association studies to identify susceptibility loci in a variety of solid tumors.

108. Broderick P, Carvajal-Carmona L, Pittman AM, et al. A genome-wide association study shows that common alleles of SMAD7 influence colorectal cancer risk. Nat. Genet 2007;39(11):13151317.1317 [PubMed: 17934461] • Illustrates the recent use of genome-wide association studies to identify susceptibility loci in a variety of solid tumors.

109. Tenesa A, Farrington SM, Prendergast JG, et al. Genome-wide association scan identifies a colorectal cancer susceptibility locus on 11q23 and replicates risk loci at 8q24 and 18q21. Nat. Genet 2008;40(5):631-637.637 [PubMed: 18372901] • Illustrates the recent use of genome-wide association studies to identify susceptibility loci in a variety of solid tumors.

110. Tomlinson I, Webb E, Carvajal-Carmona L, et al. A genome-wide association scan of tag SNPs identifies a susceptibility variant for colorectal cancer at 8q24.21. Nat. Genet 2007;39(8):984988.988 [PubMed: 17618284] - Illustrates the recent use of genome-wide association studies to identify susceptibility loci in a variety of solid tumors.

111. Tomlinson IP, Webb E, Carvajal-Carmona L, et al. A genome-wide association study identifies colorectal cancer susceptibility loci on chromosomes 10p14 and 8q23.3. Nat. Genet 2008;40(5): 623-630.630 [PubMed: 18372905] - Illustrates the recent use of genome-wide association studies to identify susceptibility loci in a variety of solid tumors.

112. Easton DF, Pooley KA, Dunning AM, et al. Genome-wide association study identifies novel breast cancer susceptibility loci. Nature 2007;447(7148):1087-1093.1093 [PubMed: 17529967] • Illustrates the recent use of genome-wide association studies to identify susceptibility loci in a variety of solid tumors.

113. Gudmundsson J, Sulem P, Steinthorsdottir V, et al. Two variants on chromosome 17 confer prostate cancer risk, and the one in TCF2 protects against type 2 diabetes. Nat. Genet 2007;39(8):977983.983 [PubMed: 17603485] - Illustrates the recent use of genome-wide association studies to identify susceptibility loci in a variety of solid tumors.

114. Gudmundsson J, Sulem P, Manolescu A, et al. Genome-wide association study identifies a second prostate cancer susceptibility variant at 8q24. Nat. Genet 2007;39(5):631-637.637 [PubMed: 17401366] - Illustrates the recent use of genome-wide association studies to identify susceptibility loci in a variety of solid tumors.

115. Gudmundsson J, Sulem P, Rafnar T, et al. Common sequence variants on 2p15 and Xp11.22 confer susceptibility to prostate cancer. Nat. Genet 2008;40(3):281-283.283 [PubMed: 18264098] • 
Illustrates the recent use of genome-wide association studies to identify susceptibility loci in a variety of solid tumors.

116. Yeager M, Orr N, Hayes RB, et al. Genome-wide association study of prostate cancer identifies a second risk locus at 8q24. Nat. Genet 2007;39(5):645-649.649 [PubMed: 17401363] • Illustrates the recent use of genome-wide association studies to identify susceptibility loci in a variety of solid tumors.

117. Amos CI, Wu X, Broderick P, et al. Genome-wide association scan of tag SNPs identifies a susceptibility locus for lung cancer at 15q25.1. Nat. Genet 2008;40(5):616-622.622 [PubMed: 18385676] - Illustrates the recent use of genome-wide association studies to identify susceptibility loci in a variety of solid tumors. 